\title{
«LA CELESTINA» FUENTE MITOLÓGICA PARA EL RETABLO DE SAN PELAYO DEL MAESTRO DE BECERRIL: COMITENTE Y AUTOR

\author{
POR .
} \\ ISABEL MATEO GOMEZ \\ Departamento de Arte del CSIC JULIÁN MATEO VIÑES
}

Licenciado en Historia por la Universidad Autónoma de Madrid

\begin{abstract}
To find the sources of the pagan fables represented In the reredos we have to search througt classic and mythological literature as well as Castilian and Italian literature of the Renaissance. The most difficult themes to identify are solved through the mythological quotations in La Celestina. The didactic and moral value of the text, its readers and the cultural environment reigning between the end of the fifteenth and the beginning of the sixteenth century lead us to suggest, together with the stylistic qualities of the reredos, the name of the patron and the author.
\end{abstract}

Durante la Edad Media y el Renacimiento Palencia fue un importante foco cultural, que desarrolló su mayor influencia desde el siglo XIII a fines del XVI. Durante este tiempo muchos de sus hijos, principalmente de Tierra de Campos,ocupan puestos importantes en la vida política, religiosa y artística del país, extendiéndose su influencia al campo de la teología y de las humanidades en sus vertientes literarias y artísticas, convirtiéndose en foco de atracción de artistas extranjeros como Juan de Flandes, de asentamiento de familias de pintores, como los Berruguete, y de importantes talleres de pintores, escultores, bordadores, orfebres y entalladores.

Entre los palentinos de Tierra de Campos más destacados en el siglo XVI encontramos a fray Mancio del Corpus Christi, llamado también de Becerril, quien fue catedrático de Alcalá en 1552 y luego de Salamanca; don Alonso Manso, canónigo magistral en Salamanca en 1437 y sacristán mayor del príncipe don Juan, hijo de los Reyes Católicos, quien, además, debió alcanzar edad muy avanzada pues fue primer inquisidor del nuevo mundo y promovido a obispo de Puerto Rico en 1512. También la familia de los Manrique, a quienes desde 1430 les había concedido Juan II la villa de Paredes de Nava, próxima a Becerril de Campos, que en el siglo XV es cuna del poeta Jorge Manrique y del pintor Pedro Berruguete, entre cuyos discípulos más directos se encuentra el Maestro del retablo de San Pelayo. 
La iglesia de San Pelayo de Becerril de Campos aparece citada en el Catálogo Monumental, manuscrito, que se hizo en 1939, y en el que se alude a una serie de tablas desmontadas, del siglo XVI, con la vida de San Pelayo y consideradas como de escuela de Pedro Berruguete o de él mismo. Las tablas debieron permanecer allí hasta los primeros años de la década de 1950 , en que fueron compradas por el cabildo malagueño. Se hallan expuestas en la catedral dentro de un retablo barroco, de forma no ordenada, y a falta de los profetas, que se hallan en colección privada madrileña procedentes de la antigua colección Adanero. ${ }^{1}$

El retablo de San Pelayo cuando fue pintado hacia la segunda década del siglo XVI debió estar insertado en un marco plateresco y, como dedicado al patrón de la iglesia, ocuparía el lugar preferente de ella.

El retablo constaba de ocho historias y un banco, ordenados partiendo del lado del evangelio de izquierda a derecha y de abajo a arriba de la siguiente forma: $1^{\circ}$ Ermogio, obispo de Tuy, en la cárcel de Córdoba, después de haber sido hecho prisionero por las tropas de Abderramán III, tras la derrota cristiana en el valle de Junquera; $2^{\circ}$ ) El obispo Ermogio entrega a Abderramán III como rehén al niño de diez años, su sobrino, de nombre Pelayo, a cambio de unos moros que se hallaban en poder cristiano y que iban a ser liberados (fig 1); $3^{\circ}$ ) El niño Pelayo en prisión predica la virtud a los soldados que le tienen prisionero (fig 4); $4^{\circ}$ ) San Pelayo flagelado en presencia de Abderramán por no querer ceder a los deseos deshonestos del califa; $\left.5^{\circ}\right)$ San Pelayo crucificado y martirizado arrancándole con tenazas partes del cuerpo; $6^{a}$ ) San Pelayo degollado; $7^{\circ}$ ) San Pelayo es elevado al cielo por ángeles desde el río Guadalquivir.

La escena central del banco estaba ocupada por la Virgen con el Niño sentada en un trono decorado con las Virtudes de Rafael, conocidas a través de los grabados de Raimondi y en el que se apoya San Juan Bautista niño.A cada lado de la Virgen dos santas mártires, Santa Agueda y Santa Catalina y, a los extremos, Salomón y David.

Sancho el Fuerte y Ramiro II tras enviar embajadas a Córdoba para recuperar el cuerpo de Pelayo,no lo consiguieron. Fue en tiempos de Ramiro III cuando tuvo lugar, trasladándose sus restos definitivamente a Oviedo donde celebran su fiesta amén de en muchas iglesias de España, especialmente en Castilla y León.

Angulo fue el primero que llamó la atención, en 1937, sobre el entusiasmo renacentista del pintor del retablo de San Pelayo por los escenarios arquitectónicos, amor al paisaje e interés por la fábula mitológica, que aparece en dos de las escenas : la de Pelayo como rehén del califa y la de Pelayo predicando en la prisión (fig 1 a 5). En el luneto de la primera historia (fig. 2) piensa Angulo que se representan amores paganos contra natura, aludiendo a los que sintió Abderramán III por Pelayo y expresados por Leda y el cisne, Lucrecia y un joven acariciando a su perro, que pudiera identificarse con Céfalo lamentando con Lelapos las trágicas consecuencias de los celos de Procris. En el segundo luneto (f ig 5) Angulo advierte la utilización por parte del pintor, de la estampa de Marco Antonio Raimondi «El hombre de las trompetas», cuyo significado se le escapó a Barts y que Angulo piensa pudiera tratarse de la ilustración de una «sentencia» de algún sabio griego o latino que pudiera relacionarla con el tema del cuadro. La utilización de la estampa de Raimondi le inclina a fechar el retablo en la primera década del siglo XVI ${ }^{2}$

Angulo vuelve a tratar estas escenas con mayor profundidad en su libro La Mitología y el Arte Español del Renacimiento, publicado en $1952^{3}$. Insiste en el escenario bru-

\footnotetext{
${ }^{1}$ MADOZ, Diccionario, tomo IV, 1846, pág 103 ; F. SIMON Y NIETO Los antiguos campos góticos Madrid, 1895, p. 136. Catálogo de la Provincia de Palencia, Manuscrito en depósito del Ministerio de Educación y Cultura en el Dpto. de Arte del Centro de Estudios Históricos del CSIC ) Tomo IV, 1939, p. 27. Inventario artístico de Palencia y su Provincia, Madríd, 1977, vol I, pág 99. ANGULO, Pedro Berruguete en Paredes de Nava , Barcelona, 1946, pág 5.

${ }^{2}$ ANGULO «El Maestro de Becerril» Archivo Español de Arte, 1937, pág 15-24.

${ }^{3}$ Madrid, pág 47.
} 
nellesquiano de la historia de San Pelayo ante el califa (fig 1), relacionándolo con la iglesia de San Lorenzo de Florencia, que el pintor pudo conocer de oídas en conversaciones con Berruguete, Picardo, Sagredo o Vigarny. Respecto a los temas mitológicos supone que el artista o su consejero debió de ser un buen lector de los clásicos, y que la alusión de los amores contra natura del califa, no sólo aparecen aludidos en Leda y el cisne, sino también en la inscripción que hay debajo del luneto donde aparece citada $P a$ sifae, famosa por sus amores con un toro. Respecto al grupo, que anteriormente había supuestamente identificado con Lelapos y los celos de Procris, no se confirma en ello sino que abre la posibilidad a que se trate de otra fábula de amor contra natura. Respecto a Lucrecia, en el centro de la composición , clavándose el puñal después de no haber podido resistir la violación de Tarquino, podía ser una alusión a la actitud de Pelayo de preferir la muerte a vivir en pecado. Por el friso corre una inscripción en capitales romanas ${ }^{4}$, que Angulo transcribe, teniendo en cuenta las interrupciones debidas a los elementos arquitectónicos (fig 3 y 2):

NIO... EI ... L... OSI..GI.. N ... PASIPHE ... MENERV...

Interesada por el tema y deseosa de intentar completar la interpretación de los interrogantes de Angulo, sugerí que «el hombre con el perro», (fig 2), compañero de Leda en el luneto, podría aludir a Ganimedes, quien pastoreaba con un perro y fue violado, como Leda, por Júpiter transformado en águila. En cuanto al segundo luneto (fig 5) supuse que podría representar a las tres musas, quienes, según Cartari, representaban «las tres artes sermocionales» por las que se llega al conocimiento de la sabiduría. Las musas eran consideradas, también, como consuelo en las adversidades y templadoras del espíritu, en una palabra, representaban la armonía del orbe por su ciencia y honesta vida.En este sentido abunda Conti, basándose en Pitágoras, diciendo que las musas con su sabiduría alejaban del espíritu de los mortales los deseos impuros ${ }^{5}$. La figura masculina cargando una piedra la identifiqué con Sisifo, cuya historia fue adaptada por la literatura y el arte como la representación de los máximos esfuerzos. Desde Ovidio y Homero a Pérez de Moya en el siglo XVI, Sisifo significa el esfuerzo del alma por obtener la felicidad. Esta interpretación del luneto, respecto a la armonía de los sentidos y el esfuerzo del alma, reflejaban y estaban de acuerdo con lo que representaba el Niño Pelayo en la historia frente a la desarmonia de los instintos del califa, expresados en el otro luneto. ${ }^{6}$

Las fábulas mitológicas no fueron frecuentes en nuestro arte en fecha tan temprana ${ }^{7}$. Sólo se justificaba su presencia por la cristianización de los temas, en el sentido con que aparecían en nuestros poetas del siglo XV. El temprano « renacimiento» literario favoreció la difusión de la fábula pagana, y la aparición de la imprenta hizo que, en 1490, ya existiera en España una traducción de las Metamorfosis de Ovidio.

Volviendo al retablo de San Pelayo, quedaban por investigar el significado de la «figura con el perro» y el de la «inscripción», que recorría el friso de la parte izquierda

\footnotetext{
${ }^{4}$ Como en la Degollación del Bautista, de Berruguete, en Santa María del Campo (Burgos), y en la escena de la Presentación del Niño en el Templo, del retablo de Terradillas, que se encuentra en la Universidad de Salamanca, y que hay que relacionarlo con el Maestro del Becerril, tal vez en una etapa más avanzada.

${ }^{5}$ I. MATEO GOMEZ «Humanismo y Mitología en el arte español del Renacimiento», Lecturas de Arte, 1990, pág 60-67.

${ }^{6}$ Solo se reducía su presencia al mundo de la miniatura y del tapiz.

${ }^{7}$ Agradezco a D ${ }^{\mathrm{a}}$ Rosario Camacho, catedrática de Historia del Arte de la Universidad de Málaga, su gestión para la obtención de las fotografías.
} 
(figs 2 y 3 ). Unas magníficas fotos de detalles de las tablas han servido para estudiarlas mejor.

En el friso se lee: E ... Đ... NIO ... ER ... VI... OSI... (Fig 3) y, por la parte del frente, debajo del luneto:GI ... PASIPHE MENERV.

También, gracias a los detalles fotográficos, pudimos observar que en el luneto (fig 2) no era un hombre el que acariciaba al perro, sino una mujer, y cómo el perro le devolvía la caricia posando una pata sobre su muslo.

La figura que se halla sentada con el cisne, a la izquierda, no ofrece duda de interpretación. Se trata de LEDA Y EL CISNE. Higinio, en sus Fábulas, cuenta como Júpiter se convirtió en cisne para poseerla junto al rio Eurotas. Fulgencio, moraliza sobre este suceso interpretándolo como un reflejo de la injusticia, y Boccacio, en la Genealogía de los dioses paganos. (Libro XIII, cap. VII) insiste en la historia contada por Higinio pero añadiendo que después de violada «levantó pasión en ella» ${ }^{8}$.

La mujer del centro, clavándose el puñal, es sin duda LUCRECIA. Pero, si su iconografía no ofrece duda de identificación, si la ofrece la interpretación de su papel en esta historia del luneto. Si generalmente representa la «castidad» por haberse dado muerte después de haber sido violada por Sexto Tarquinio, quien suplanta a su marido, algunos autores han supuesto que esta violación -como dijo Higinio en el caso de Leda- levantó pasión en ella. También se refieren a Lucrecia como «necia» porque, si realmente fue violada, no tenía por qué haberse dado muerte.

Entre los que la consideran «casta» y representación didáctico moralizadora, se hallan, Valerio Maxímo, Plutarco, Santa Clara y Boccaccio. También en nuestra literatura del siglo XV y XVI defienden esta postura, Gómez Manrique con cierto deje de ironía: «Que por enxemplo vulgar / devemos todo tener de Lucrecia su matar»; Juan de Mena en el Laberinto de la Fortuna (LXIII) - «Sobre todas la casta lucrecia / con ese cuchillo que se disculpó», y, en las Coplas contra los siete pecados mortales (VIII), alaba la castidad de Lucrecia y la fuerza de Tideo ${ }^{9}$. Fernán Pérez de Guzmán proclama su admiración por ella, «La perfecta continencia / de Lucrecia predicada», y su honestidad también se resalta en los Avisos para cuerdos de Diego López de Haro.

En un interesante trabajo. J. E. Guillet espiga en la literatura desde el siglo XV al barroco, enfatizando sobre el aspecto de la consideración que tuvo Lucrecia como «necia» y en la referencias irónicas sobre su castidad $»^{10}$. Cita a Tertuliano como el primero que se había preocupado sobre el motivo y consecuencias del suicidio de Lucrecia. Después alude también a San Agustín, quien hizo disquisiciones sobre si Lucrecia se mató sabiéndose inocente o consciente de su culpa. San Agustín, a propósito de la licitud del suicidio, matiza que éste, en el caso de Lucrecia, no se llevó a cabo por amor a la castidad, sino por vergüenza (Libro I, Cap.

${ }^{8}$ IGINIO, Fábulas Mitológicas Clásicas. Madrid, ed. Coloquio, 1987. fab. oำ 71. FULGENCIO, se ha consultado a través de GONZALEZ ZARATE. Mitología e historia del Arte, Vitoria, 1997, p. 20; BOCCACCIO La Genealogía de los dioses paganos. Madrid, Editora Nacional, 1983. La obra de Bocaccio se encuentra en casi todas las bibliotecas de nuestros lectores de fines del XV y XVI; J. DE MENA, Obras Completas, Madrid, ed. Turner, 1954 (con anotaciones del Brocense). Mena no alude a la historia de Leda con Júpiter, sólo se refiere a ella como madre de los violadores Castor y Polux.No es frecuente en nuestra literatura del XV la mención a Leda. Curiosamente tampoco aparece en la Metamorfosis de Ovidio, y, algunos autores como Virgilio, citan su nombre pero no la historia, en la Eneida (Libros 1, 652; 111, 328 ; VII, 364)

${ }^{9}$ Creemos importante resaltar que Tideo se considere un ser vengativo y que Lucrecia también lo fue cuando solicitó, de su esposo y padre, venganza sobre Tarquino.

${ }^{10}$ «Lucrecia necia» Hispanic Review, vol. XV, 1947, pág 120-136. Hemos seguido el texto de San Agustín en La Ciudad de Dios marcando los libros que tratan del problema. 
16-19). Al final de todo el proceso disquisitivo, el santo acepta, pero no muy convencido la versión tradicional de su castidad. Interesa la postura de San Agustín referente a la licitud de desear la muerte siempre que conlleve la intención de no caer en el pecado, por lo que tiene en común con la actitud de Pelayo de preferir la muerte antes de ser violado (Libro I, cap 26-27). ${ }^{12}$

Retomando la duda de Tertuliano y San Agustín sobre la castidad de Lucrecia, Torres Naharro, en el siglo XVI, dice en la Comedia Tinellaria : «Más es necia / Harto le digo: Lucrecia / Conserva bien mi partido / Ve, que tu me manternas / más otro me gozará / ¡Que placer? / Como le hago creer / Que las piedras son pan tierno». Lucas Fernández dice en la Farsa o cuasi comedias : "Qualquíer dama si no es necia / antes se deve matar / que no errar / o muera como Lucrecia». También Diego de Valera, en Ladania de Amores, invoca a Tarquino - el violador de Lucrecia- junto a los santos confesores, refiriéndose a él como persona: «que muchas penas pasastes» ${ }^{13}$.

Queremos también citar otras alusiones a Lucrecia en el siglo XV donde se la relaciona con otras mujeres famosas, cuyas actuaciones, como la de ella, fueron dudosas, así como algunos textos donde acepta la pena que se le imponga. El Marqués de Santillana en sus Proverbios Glosados la alaba junto a Dido y Diana; el Maestre Johan Galmez, franciscano español del siglo XV, en las Quatro Virtudes Cardinales, describe a Lucrecia haciéndola a ella responsable de lo sucedido: «yo de mi pecado me absuelvo, mas de la pena non me libro»; Diego de San Pedro, en la Cárcel del Amor la hace declarar, «aunque el cuerpo fue forzado, quedó el corazón inocente, porque soy libre de culpa; más no me absulvo de la pena». En este sentido se expresa tambien el popular romance de Tarquino y Lucrecia, en el Cancionero de Romances (ca 1545-5), y en Dante, quien la coloca entre los héroes nacionales pero como suicida, la condena al infierno (canto IV, 128) ${ }^{14}$.

Como vemos son varias y distintas las consideraciones sobre Lucrecia. Para su interpretación en el luneto habrá que tenerse en cuenta al resto de las figuras e inscripciones que la acompañan.

Otra figura problemática, hasta ahora, para su identificación es la que aparece en el mismo luneto, emparejada con un perro y acariciándose mutuamente. En nuestro espigue por la literatura fabulística, antigua y medieval, de primera y segunda mano, no hemos encontrado ninguna alusión que pudiera corresponderse con ella. Ha sido a través de una reelectura de la Celestina donde hemos localizado un pasaje que la describe junto a otro personaje femenino aludido en el friso, que hay debajo de ella. En efecto, en el Acto I del libro de Fernando de Rojas - del que celebramos este año el quinto centenario de su aparición, y al que Cervantes llamó «divino»-, el criado de Calixto, Sempronio, vitupera a las mujeres como arma del diablo, pecado y destrucción del paraíso: «desespera alcanzar a una mujer, muchas de las cuales en grandes estados constituidas se sometieron a los pechos y resuellos de viles y acemileros y otras a brutos animales $¿$ No has leido de PASIFE con el toro, DE MINERVA CON EL CAN?».

La diosa Minerva siempre es descrita como imagen de la Virginidad y de la Sabiduría. Sin embargo, en La Celestina, se la describe en una aventura contra natura similar a las de Pasifae y Leda. Este atrevimiento de emparejar a la casta diosa con las otras figuras femeninas,

\footnotetext{
${ }^{12}$ loc. cit nota 11. La literatura barroca de Lope de Vega, Mira de Amescua, Góngora, Ruiz de Alarcón, Tirso de Molina y Sor Juana Inés de la Cruz, aluden a Lucrecia en sentido negativo.

${ }^{13}$ Cancionero del siglo XV ca 1360-1520. Recopilado por B. DUTTON, vol I, Salamanca, 1990, pág. $537-538$.

${ }^{14}$ loc. cit. nota 11 .
} 
que habían tenido amores ilícitos con animales, hizo investigar a Green este texto celestinesco. En un artículo este autor sugiere que como al parecer la primera edición del libro de 1499 tuvo erratas, deberíamos leer en lugar de «con el can » con «Vulcan». Se basa en que, a través de versiones preliterarias, se sabe que Minerva tuvo una relación de estupro con Vulcano de la que nació Erictonio. Recogida la historia por Lactancio, el resto de los autores, desde Eurípides, defienden la castidad de la diosa. Green piensa que Rojas tomó la idea de Vulcano no de Lactancio sino de Servio en Virgili Georgicas (I, 205); donde se insiste en el estupro entre ambos, viendo el error del texto de La Celestina en una mala lectura del impresor, quien imaginó un paralelo entre el «toro» de Pasifae y el «can» de Minerva ${ }^{15}$.

Russell en su edición crítica de La Celestina ${ }^{16}$ insiste en que la mitología antigua no habla de ninguna relación sexual de Minerva con este animal. Respecto a la tesis de Green, la rechaza, porque Minerva no tuvo relaciones con Vulcano y el pasaje de la Celestina, requiere que la relación sea con un animal y no con un hombre. Supone que se trata de un error intencionado por parte de Fernando de Rojas para ridiculizar al criado Sempronio haciendo citas clásicas. ${ }^{17}$.

Sea cual fuere el origen o motivo de la cita de Rojas el hecho es que el pintor o comitente de la historia de San Pelayo, se inspiró en el texto de La Celestina. para representar un pecado contra natura que estuviera acorde cón el de Leda y el de Pasifae.

Hemos localizado dos alusiones a Minerva en relación con amores ilícitos en el Laberinto de la Fortuna (LX) de Juan de Mena, y en Cristóbal Suarez de Figueroa, en su Plaza Universal (Discurso LXXI). Se refieren a ello, respectivamente, de la siguiente manera: «El humano seso se ciega y oprime / en las bajas artes que le da Minerva», y el segundo hablando de las rameras que sufren por sus amantes dice:«Las lágrimas de Dido por Eneas, aquellos llantos de Eco por Narciso, aquellas palabras de Pallas enamorada y aquellas promesas que hizo Juno a Paris».

No cabe duda que tanto el pintor como el comitente pensaron que ésta aventura o representación de Minerva con el can, no iba a ser reconocida teniendo en cuenta la fama virginal de la diosa. Por ello, seguramente, pusieron debajo de ella, en el friso arquitectónico, su nombre, MENERVA, para que no hubiera dudas sobre lo representado (fig 2).

A la izquierda de este nombre aparece el de PASIPHE, siguiente ejemplo de deseo contra natura expuesto por Sempronio en La Celestina y que vuelve a aparecer en el Acto XVI, de la misma obra como «la mujer de Minos, que lo engañó con el toro».

Apolodoro analiza el suceso de Pasifae como el resultado del amor monstruoso y bestial que sintió por el toro enviado por Poseidón a su esposo el rey Minos. Higinio en la Fábulas

\footnotetext{
${ }^{15}$ «Celestina, Auto I: Minerva con el can » Nueva Revista de Filología Hispana, vol VII, 1953, pág 470-474.

${ }^{16}$ Madrid, ed Castalia, 1991 cap. de Fuentes.

${ }^{17}$ La Celestina. Ed. Crítica de Peter Russel, Castalia, Madrid,1991, cap. de Fuentes. No pensamos como Russell porque, precisamente Sempronio, en este mismo Acto, hace una cita exacta de un Sermón de San Pedro Crisólogo. Más bien creemos que lo mismo que existieron evangelios y textos apócrifos como los «Bocados de oro», que eran textos sapienzales amorosos en la Edad Media (CATEDRA GARCIA Amor y Pedagogía, Salamanca 1989), pudo haber "mitologías apócrifas". Desde luego, en la biblioteca de Fernando de Rojas había unas «fábulas de Ovidio en romance» que Fernando del Valle Lersundi ha identificado con el Libro de Metamorphoseos y fábulas del excelente poeta y philósofo Ovidio noble caballero patricio romano. Sin lugar, sin año, pero de la primera mitad del siglo XVI y probablemente impreso en España. Traducido por Jorge de Bustamante, natural de Silos (vid. «Testamento de Fernando de Rojas, autor de la Celestina»; en Revista de Filología Española, 1929, vol. XVI, pags 366-388. R. SCHEVILL, en Ovid and the Renacence in Spain, HildesheimNewYork, 1971, p. 246, dice, que la primera versión en España (la del mismo título arriba expresado) es la más importante y debió de ser muy popular y ampliamente leída. La versión de Jorge de Bustamante fue impresa antes de 1546 y existe otra de Pedro Sánchez de Viana de 1589. El libro $6^{\circ}$ está dedicado a «Palas» y los sucesos amorosos de Júpiter con mujeres se despacha con un verso o dos. Todavía hay una alusión mas en La Celestina sobre el "bestialismo", cuando Sempronio refiere cómo la abuela de Calixto se acostó con un «ximio».
} 
(52) dice que la culpa la tuvo Venus, quien infundió en Pasifae un amor monstruoso hacia un toro, que había enviado Neptuno, y que después de copular con él, nació el minotauro ${ }^{18}$. Boccaccio moraliza sobre el tema señalando que significa el amor funesto: «considero en efecto que los antiguos han pretendido mostrar de que manera se origina en nosotros el vicio de la bestialidad por este argumento» y «procurando, siguiendo el juicio de la sensualidad, abusamos o deseamos abusar de ella, caemos en la concupiscencia bestial» ${ }^{19}$. El Marqués de Santillana lo cita brevemente como señal de infortunio en la Comedieta de Ponza (XLVIII), y Juan de Mena, en el Laberinto de la Fortuna (CIV): «... y vimos, venidos un poco delante / plañir a Pasiphe sus actos indignos / la cual antepuso el toro a ti Minos / no hizo Scilla troque semejante». Natale Conti en su Mitología ${ }^{20}$ advierte que Cicerón en el libro Sobre la Naturaleza de los Dioses (III, 19-18), al referirse a Pasifae dice que ésta no está incluida entre los dioses y que Virgilio en la Eneida (libro VI, 24-30) la describe así: «Aquí está el amor del cruel toro y Pasifae a él sometida mediante engaño y la naturaleza mezclada». Conti interpreta la historia moralizadoramente, aclarando que los antiguos entendían por esta fábula la naturaleza de las almas, representando Minos a los justos y Pasifae al placer ilegítimo.

No cabe duda que la dificultad que presentaba la representación de Pasifae con el toro llevó al pintor a reducirla simplemente a la inscripción de su nombre. Ya Panofsky nos advierte sobre estas dificultades cuando se refiere a la representación del Rapto de Europa en un Ovidio Moralizado del siglo XIV ${ }^{21}$.

A la izquierda del nombre de Pasiphae, entre dos capiteles, aparecen inscritas dos letras: GI (Fig 3), hasta ahora sin identificar, y que pensamos podrían constituir la primera sílaba del nombre de GIUPITER, dios lascivo, quien precisamente se transforma en cisne para violar a Leda. Ciertamente que en latín no se escribe así sino «Jupiter» pero sabemos, que la ortografía latina era bastante deficiente en España incluso en personas de cierta cultura. Así el Brocense corrigió la ortografía de los nombres propios latinos cuando trató El Laberinto de la Fortuna de Mena ${ }^{22}$. El funcionamiento de los estudios del latín en nuestro país y su expansión no eran fáciles a pesar de que, desde el siglo XIII, se daba por descartado que la vía del acceso al saber era su conocimiento. Desde el siglo XIV solamente el clero tenía acceso a su aprendizaje a través de escuelas que había en las propias catedrales. Pero, muchos clérigos, que ejercían su magisterio en lugares apartados, se resistían a abandonar sus iglesias para ir a estudiar, en muchos casos por razones económicas. Otras causas que contribuyeron a que la cultura latina no se extendiese fueron, por un lado, la expulsión de los judíos, con lo que se perdió una burguesía que pudo favorecer la expansión del humanismo, y por otro, razones simplemente económicas. En 1532, los libros de los claustros de la Universidad de Salamanca estaban redactados en castellano o en una curiosa mezcla de vernáculo y latín, introduciéndose pintorescos barbarismos. Los españoles escribían en latín tan burdamente que delataban al punto su nacionalidad y el autor de Viaje a Turquía llamaba «Música barbaresca» al latín macarrónico de los españoles de fines del siglo XV y comienzos del XVI, pero no sólo refiriéndose a la plebe, sino a los universitarios. Las incorrecciones latinas se permitían_y los comentarios mitológicos se hacían siguiendo el método alegórico ${ }^{23}$.

\footnotetext{
${ }^{18}$ loc. cit. nota 8.

${ }^{19}$ loc. cit. nota 8 (Libros IV, Cap. X y Libro XI, Cap. XXVI).

${ }^{20}$ Ed. de la Universidad de Murcia, 1988, p. 732.

${ }^{21}$ PANOSFKY, E: Estudios sobre Iconología, Madrid, 1972, p. 36.

${ }^{22}$ loc. citada nota 8

${ }^{23}$ GIL FERNANDEZ, L. Panorama del humanismo español (150-1800). Madrid, 1981, $1^{\circ}$ parte, Cap. 1-4, 8-9.
} 
Después de este panorama, respecto al uso del latín, podemos aceptar la palabra como GIUPITER formando parte de la inscripción del friso casi debajo de su historia lasciva con Leda. De otro lado, la palabra MENERVA coincidía -como aclaración- a la historia de Minerva con el can. Ahora bien, ¿Que relación podrían tener PASIPHE y LUCRECIA?. La dificultad está en la dualidad apreciativa existente entre considerar a Lucrecia casto o no. Y nos atrevemos a sugerir que en este caso se ha elegido la segunda opción, pues tanto Lucrecia como Pasiphe se dejaron llevar por el placer ilegítimo. En ambas -y también en Leda- la violación levantó pasión en ellas y en los casos de Pasiphe y Lucrecia los maridos son justos e incluso Tarquino, el violador de Lucrecia, es defendido por algunos autores. La escena de este luneto del fondo, sirve de telón alusivo y explicativo, de los deseos deshonestos, ilegítimos y contra natura del califa Abderraman III hacia el niño Pelayo.

Esta manera de criticar el vicio contra natura aparece en los clásicos, Ovidio, Marcial y Juvenal, quienes reprenden vicios sensuales ${ }^{24}$. También Santo Tomás en la Summa habla del comercio ilícito contra natura entre humanos y animales (II.II, 9154 ; 11-12). Finalizamos con Juan de Mena en el Laberinto de la Fortuna (CI) a propósito de este tipo de deseo. «Eran adúlteros y fornicarios / y otros notados de incestuosos / y muchos que juntan tales criminosos.../ y los maculados de crimen nefando de humana razon en todo contrarios».

Ahora pasamos a la inscripción que recorre el friso lateral izquierdo: "E ... ๑ ... NIO ... ER ... VI ... OSI, cuya lectura a nuestro entender sería: «ENEAS, DIDO, ASCANIO, PUER VIRTUOSI». La inscripción se halla justo debajo de unas figuras que, a modo de relieve como las del luneto, representan a un hombre con un niño que se agarra a su brazo ${ }^{25}$. Virgilio en la Eneida (Libro II, 651-652) narra la historia de Eneas cuando vuelve a casa de sus padres después de la ruina de Troya: «Nosotros oponiéndonos, dando suelta a las lágrimas, mi esposa Creusa, Ascanio / y toda la familia suplicábamos no lo arruinara todo nuestro padre en su ruina». Ascanio es citado en muchos pasajes del libro, pero es en el de la "Huida" cuando su referencia está más en relación con la representación de nuestra pintura: Que a mi lado venga (dice Eneas) el pequeño Julo (también llamado Ascanio)» y «Mete el pequeño Julo en mi diestra los dedos de su mano, y va siguiendo a su padre con pasos que no igualan a los suyos» (710. 724-725).

Eneas es el héroe virtuoso y padre amantísimo de Ascanio. Al niño también se le describe en la Eneida (Libro III, 339) como ser lleno de virtud, de valor y aspirante a las «auras del cielo», descripción evocadora de la historia del niño Pelayo, como lo son también, la de considerar a Ascanio como ejemplo del alma buena merecedora de premio (libro IX, 256).Dido, reina y fundadora de Cartago, cuenta Virgilio que se clavó la espada en el pecho antes de tirarse a la pira de fuego por no soportar la marcha de Eneas del que estaba profundamente enamorada (Libro IV, 65-70) ${ }^{27}$.

Todos ellos, Eneas, Dido y Ascanio, además de aparecer en Virgilio, los encontramos unidos en el Acto VI de La Celestina, evocados por Calixto a propósito del amor puro:«De cierto creo, si nuestra edad alcanzara aquellos pasados Eneas y Dido, no trabajara tanto Venus

\footnotetext{
${ }^{24}$ Dictamen de Jerónimo Zurita acerca de la prohibición de obras literarias por el Santo Oficio». Revista de Archivos Bibliotecas y Museos, 1903, Tomo VIII, p. 218.

${ }^{25}$ Agradezco a mi compañero Ricardo Olmos, Investigador del Departamento de Arqueología del C.S.I.C. su indicación de que ...NIO podía referirse a Ascanio.

${ }^{26}$ Biblioteca Clásicos de Gredos, Madrid, 1992.

${ }^{27} \mathrm{M}^{\mathrm{a}} \mathrm{R}$. LIDA «Dido y su defensa en la literatura Española» Revista de Filología hispánica. Buenos Aires- Nueva York, 1942 (p. 209-252 y 313-382), 1943 (p 40-50) ; E. LEUBE, Fortuna in Kartago-Die Eneas - Dido - Mythe Vergis in den romanischen Literaturen von 14 zum 16 fahrhunderts. Heidelberg, 1969; Gabriel Lobo Lasso de la Vega, Tragedia de la honra de Dido restaurada Reihenberg, 1926.
} 
para atraer a su hijo al amor de Elisa, haciendo tomar a Cupido ascánica forma para la engañar...». Este engaño de Venus referido por Fernando de Rojas, está inspirado en la Eneida (Libro I, 659), en el que la diosa traza un plan suplantando al virtuoso Ascanio por Cupido haciéndole parecerse a aquel. Según Russel en sus comentarios a La Celestina, Cupido adopta la forma de Ascanio para que Dido le ame ${ }^{28}$. Los protagonistas de esta parte del friso, representan la honradez, honestidad, inocencia y renuncia al amor ilegítimo, convirtiéndose Ascanio en fiel precedente clásico del virtuoso niño Pelayo.

Ya nos hemos referido al principio de este trabajo a la interpretación que dimos a la escena del Niño Pelayo predicando en la prisión (figs. 4 y 5) como la armonía de los instintos representada por tres MUSAS y del esfuerzo del alma representado por el de SISIFO. Hoy nos confirmamos en esta interpretación pero sumamos algunos textos que nos parecen de interés. En primer lugar en el Poema de Empendocles (1르 Parte I, 18) hay una referencia a 1a firmeza de la esfera, que aparece en manos de dos musas en la pintura (fig 4),como símbolo de la armonía. Boccaccio en la Genealogía de los dioses, se refiere a las musas en varios pasajes. En uno de ellos, fundándose en San Isidoro, dice que en ellas se buscaba la norma de vida, y Fulgencío ellas representan los modos de doctrina y ciencia (Libro 11, cap. II). En otro libro, Boccaccio afirma que las musas no pueden ser corrompidas por el ingenio lascivo (Libro 14), concepto que está en relación con la historia que se representa del niño Pelayo. Juan de Mena en Coplas contra los siete pecados mortales (I), considera a la «voluntad» -que no le falta a Pelayo -como «cristiana musa», y en la Coronación dice que representan la gloria de los buenos: «los sus vuelos virginales / de aquestas doncellas nueve» (XXXIX y XL). Santíllana las invoca en la Comedieta de Ponza (XCIV) y finalmente, Conti, Pérez de Moya y Ripa dicen de ellas que fueron el mejor remedio contra el halago de los placeres y eran ánimas de los orbes celestiales, portando Talía y Urania el orbe como representación de las costumbres respetables. ${ }^{29}$ Respecto a Sísifo, Conti recoge la narración de su esfuerzo a través de los poetas clásicos ${ }^{30}$.

Boccaccio en su tan citada Genealogía de los dioses paganos (Libro XIV) advierte, que aunque hay muchos que critican la utilización de la fábula, ésta es más útil que perjudicial, afirmando lo conveniente que es una imagen como modo de hablar (o representar) ejemplos y ficciones (Libro XIV). Ya Santo Tomás siguiendo a Aristóteles afirmó que el hombre no puede comprender sino es con la apoyatura de las imágenes plasmando en obras artísticas cuestiones pedagógicas, enriqueciéndo el hombre un lenguaje sagrado gracias a la fusión mística entre la palabra y la imagen. ${ }^{31}$

En el siglo XV los místicos paganos son considerados teólogos dignos de ser respetados como los autores cristianos. No nos debe chocar, pues, la utilización de la fábula en sentido pedagógico para la comprensión del retablo de San Pelayo, encontrándonos ante unos recursos poéticos de la mitología, aplicados al arte didáctico-moralizador, aceptados desde el siglo $\mathrm{XV}$ para embellecer lo que se quiere expresar.

Para llegar a un conocimiento aproximado del comitente del retablo debemos destacar que el Marqués de Santillana, Mena e incluso Fernando de Rojas, entre otros, tenían en sus bibliotecas las Metamorfosis de Ovidio, el Ars Amandí, glosado por Alonso de Madrigal, y la

\footnotetext{
${ }^{28}$ loc. cit. nota 12, p. 346, nota 50. 50. según Panofsky, loc. cit nota 12, Eneas y Dido aparecen como una elegante pareja en el arte medieval.

${ }^{29}$ Conti, loc. cit nota 20, pag 545; PEREZ DE MOYA, Filosofía secreta, vol I, p. 204 y II, p. 94, Madrid117-14.

${ }^{30}$ loc cit nota 20 , p. 449.

${ }^{31}$ Santo Tomás, Summa . B.A.C. Madrid, 1963, Vol. II cap. Teoría Escolástica del Arte. pág. 650-657.
} 
Genealogía de los dioses paganos, de Boccaccio ${ }^{32}$. Nuestros poetas y escritores del siglo XV se esforzaron por formar sus bibliotecas y tanto en ellos como en clérigos y juristas hay cierta impronta de humanismo ${ }^{33}$, que es lo que se percibe en el retablo de San Pelayo.

En España la nobleza hubiera podido jugar un papel importante de mecenazgo y algunosnobles lo hicieron como los Mendoza, Tendilla, etc. , pero por su quehacer de gobierno y, milicia hay que buscar «mecenas menores», como los denomina Gíl Fernánde $z^{34}$, que se inclinaban más que por el puro humanismo, de creación literaria, por el goce de las artes plásticas.

Después de exponer los textos inspiradores de las fábulas del retablo y concretamente del libro de La Celestina, debemos preguntarnos quienes tuvieron la posibilidad de leer estos libros. Desde luego tenían que tener recursos económicos porque los libros eran caros, pero, aunque existen documentos que acreditan que algún proletario o artesano tenía libros a fines del siglo XV, los auténticos lectores estaban en el clero, nobleza y altos funcionarios, profesores y miembros de profesiones liberales entre los que se contaban los pintores.

La Celestina tuvo un exito resonante y duradero desde que apareció su primera edición en 1499 y a lo largo del siglo XVI. Fue elogiada por Vives, Valdés, Palmireno, Mal Lara, Covarrubias y Cervantes en el Celoso extremeño. Se encontraba con mucha frecuencia en bibliotecas particulares, castellanas, catalanas y de otros lugares de nuestro país, no sólo en castellano, sino traducida al italiano. Todos los que la poseyeron eran lectores cultos y doctos e incluso Isabel Clara Eugenia cita el libro en una carta al duque de Lerma. Fernando de Rojas concibió la obra -según Bataillón-como un exemplum o breviarium de moral práctica y en este sentido fue interpretada por Vives y otros durante el siglo de Oro ${ }^{35}$. Fernando de Rojas nos dice en el prólogo que podría leerse La Celestina a varios niveles: unos como sentencias morales, didácticas y edificantes y otros, a lo desenfadado y cínico. En la introducción amonesta a los que «aman» para que abandonen los vicios del amor, y, en la edición de 1502, de Sevilla, concluye :«No dudes si hayas vergüenza lector / narrar lo lascivo que aqui se te muestra; que siendo discreto verás que es la muestra por donde se vende la honesta labor / consiente cosquillas de alto consejo / con motes y trufas del tiempo mas viejo : escritas a vueltas le ponen sabor ...».

Podemos pensar a través de todo ello que un clérigo de Becerril de Campos pudo ser el comitente del retablo. Sin embargo, el conocimiento literario no sólo de La Celestina, sino de Ovidio, Virgilio, Boccaccio y de nuestros poetas del siglo XV, hacen pensar en alguien relacionado con el ambiente literario de la época poseedor de una biblioteca o familiarizado con los clásicos y, por supuesto, de Tierra de Campos ${ }^{36}$. Allí podemos imaginar a los Gómez Manrique, uno de los cuales, el famoso poeta Jorge, fue conde de Paredes. Otro Gómez Manrique, también poeta, era sobrino del Marqués de Santillana, con quien mantuvo correspondencia a propósito de la defensa contra todos aquellos que se oponían a las letra y estudios humanísti$\cos ^{37}$. Este Manrique escribe precisamente en los Consejos a Diego Arias, sobre la caducidad

${ }^{32}$ M. MORAGON, «Los recursos poéticos de la Mitología clásica» Revista de Archivos, Bibliotecas y Museos, 1955, $\mathrm{n}^{\mathrm{0}} 2$, p 549.

${ }^{33}$ GIL FERNANDEZ, loc. cit. nota 23, 22 parte.

${ }^{34}$ loc. cit. nota 33 .

${ }^{35}$ M. CHEVALIER, Lectura y lectores en la España del siglo XVI y XVII. Madrid, 1976. Es interesante también el estudio de Américo Castro de La Celestina como contienda literaria,destacando en él la mezcla de lo profano con lo religioso y la subversión de valores, tan típica de la época, así como su carácter atemporal. No cree que tenga nada que ver con Erasmo ni con la Nave de los Locos, de Sebastián Brandt, pero curiosamente no puede evitar el citarlos. Madrid, Revista de Occidente, 1965.

${ }^{36}$ Concretamente en Becerril de Campos existe una rama de los GOMEZ MANRIQUE (V. GARCIA CARRAFFA, vol. 39).

${ }^{37}$ SANTILLANA, Marqués de: Obras Completas. Madrid, Planeta, 1988. Estudio crítico. 
de los placeres y, en el mismo sentido, un libro sobre la Prosecución de los vicios y virtudes, sobre el desorden del mundo, además continuó el «Tratado de los Pecados Mortales», de Juan de Mena. Todos estos Gómez Manrique mantuvieron relación con otros poetas de su tiempo pero, por la fecha, no pudieron ser los mentores directos del retablo de San Pelayo. Si podemos considerar la posibilidad de que pudiera haber sido cualquier hijo del tercer conde de Castrogeriz, Rodrigo de Mendoza y de la Cerda, casado con Ana Manrique. Entre esta descendencia destacaríamos a Alvar Gómez Manrique, cuarto conde de Castrogeriz, y a Gómez de Mendoza Manrique, llamado Gómez Manrique. Todos ellos vivieron en la primera mitad del siglo XVI y estuvieron, por tradición familiar, en contacto con ese mundo literario ${ }^{38}$. Tampoco queremos olvidar como posible mentor -dentro de los Manrique- a Antonio Manrique de Lara, hijo de Rodrigo Manrique, primer conde de Paredes, cardenal en 1531, y fallecido en 1538. Fue Obispo de Badajoz y protegido de Carlos V.

Respecto al pintor del retablo, Angulo supuso que, la vinculación de su estilo con Pedro Berruguete podría tratarse de su yerno, Juan González de Becerril, quien le acompaña a Toledo y trabaja con él en la Catedral. ${ }^{39}$ Sabemos muy poco de él y todo se mueve en el campo de la hipótesis. Se sugirió que podría ser el autor del retablo de Horcajo de la sierra ${ }^{40}$ cuyo interés por los elementos arquitectónicos y arqueológicos del mundo florentino y romano y por los modelos femeninos, le emparentan con el pintor del retablo de San Pelayo. Lo mismo ocurre con el maestro de las tablas que se conservan en la Universidad de Salamanca, procedentes de Terradillos. Estos retablos citados constituirían el comienzo, la etapa media y la final en el desarrollo de la obra de Juan González de Becerril, pintor que sobrepasa la calidad e interés de otros pintores contemporáneos.

Aunque la personalidad artística de Pedro Berruguete ha sido estudiada recientemente ${ }^{41}$, quedan muchos aspectos por aclarar. Su paso por Urbino, en un ambiente humanista como el de Federico de Montefeltro, hace pensar en contactos del pintor no sólo con lo artístico sino con lo literario para poder llevar a cabo la decoración del Studiolo del palacio, ¿Que conocemos de los libros que pudo conocer en España y de los que pudo traerse el pintor?. Precisamente Sanchez Canton y luego Lafuente Ferrari, relacionaron las frases castellanas escritas en el libro que San Alberto Magno sostiene en el Studiolo, referēntes al falso y engañoso mundo, con las que aparecen en el Doctrinal de Privados del Marqués de Santillana. Pero, estos conceptos aparecen también en el libro arriba citado de Gómez Manrique sobre el desorden del mundo, en La Celestina, en otros poetas castellanos como Juan de Mena y en De Rebus familiar, de Petrarca. Pedro Berruguete sabemos que coincide en Paredes de Nava con Gómez Manrique, y de la generación posterior a ellos son, los Manrique de la rama de Castrogeriz y el pintor Alonso González Becerril, yerno como hemos dicho de Berruguete. Por lo que pensamos que el retablo de San Pelayo debió ser el resultado de la comunión de un comitente de la familia de los Manrique, de un pintor, vinculado a la tierra como González Becerril y de un párroco, del mismo lugar, Becerril de Campos, a los que no le eran ajenos el ambiente literario de la fábula mitológica al servicio de la iglesia.

\footnotetext{
${ }^{38}$ GARCIA CARRAFFA, vol 39. Entre otros hermanos está Rodrigo de Mendoza Manrique, dean de Toledo en 1532 y Juana de Mendoza Manrique que casa en 1525 con Lorenzo Manuel, tercer señor de Belmonte de Campos.

${ }^{39}$ ANGULO, loc cit nota 2 . POST A History of Spanish Painting. Cambridge, 1947, vol IX, I, p. 449.

${ }^{40}$ I. MATEO GOMEZ «El Retablo de Horcajo de la Sierra: su autor y filiación artística» en III Jornadas de Arte : Cinco siglos de Arte en Madrid (XV-XX). Madrid, CSIC, 1991, pag 283.

${ }^{41}$ P. SILVA MAROTO, Pedro Berruguete. Salamanca 1998.
} 


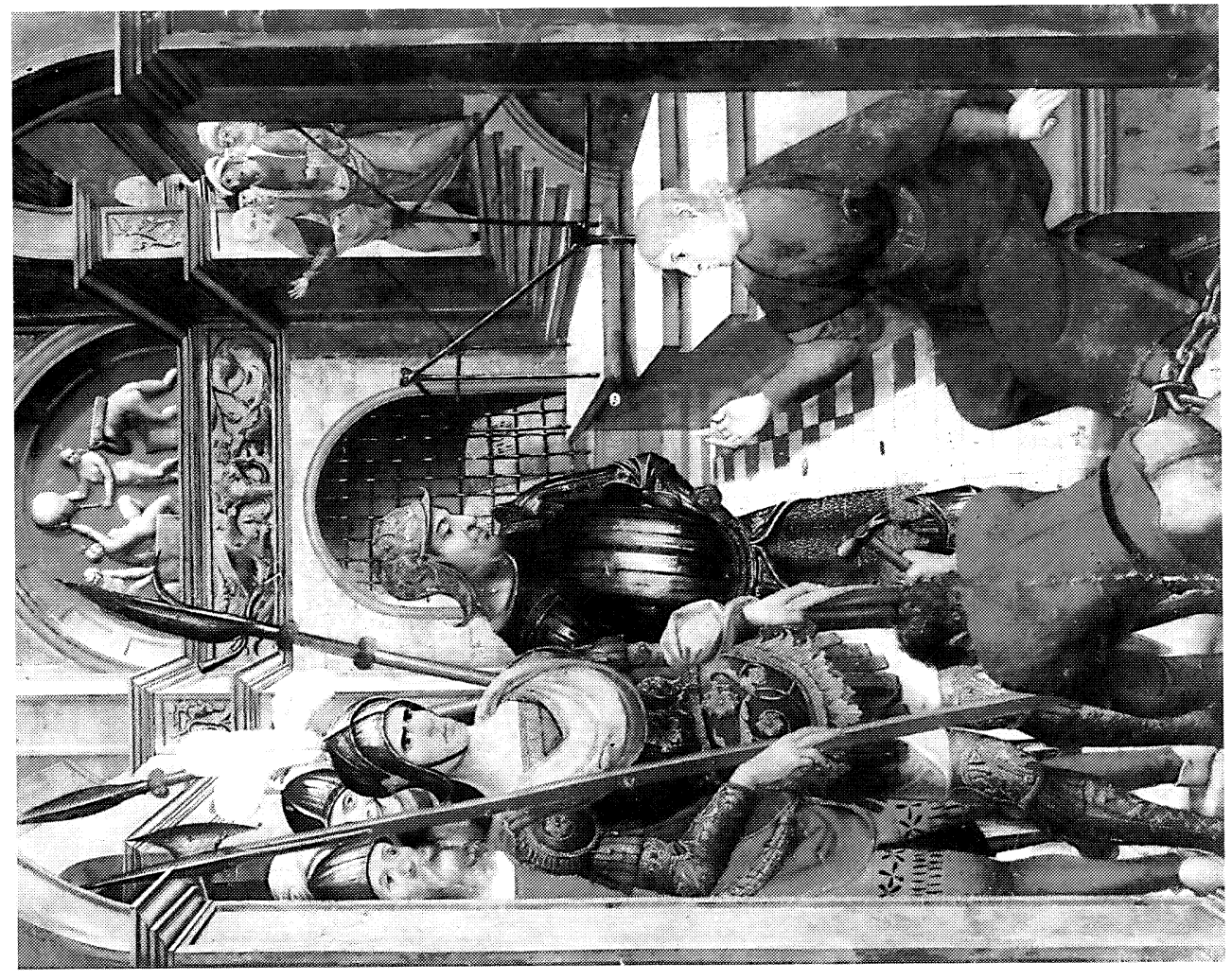

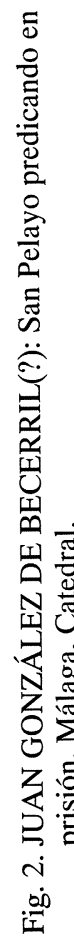

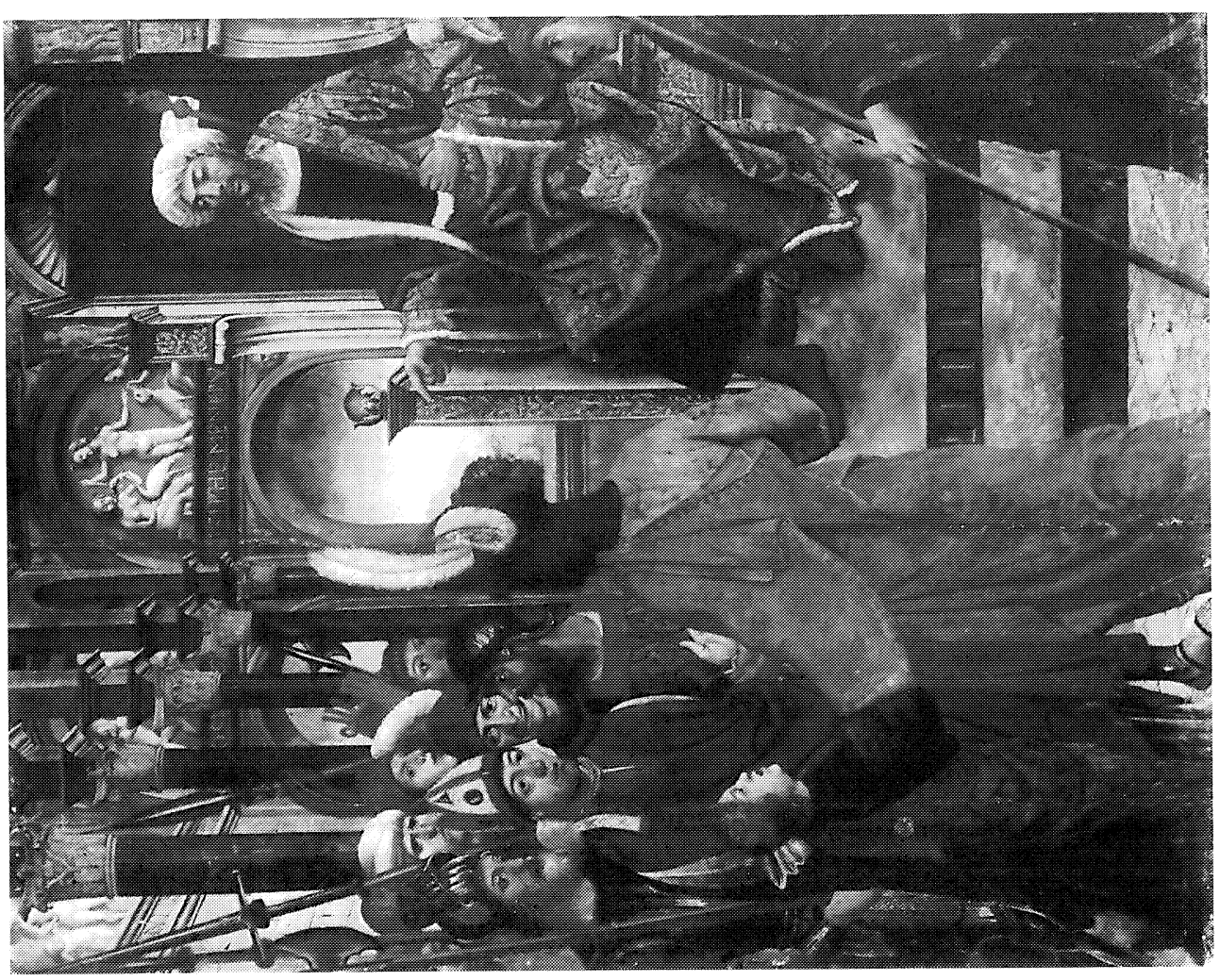

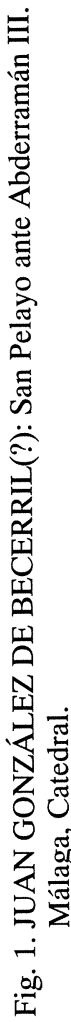




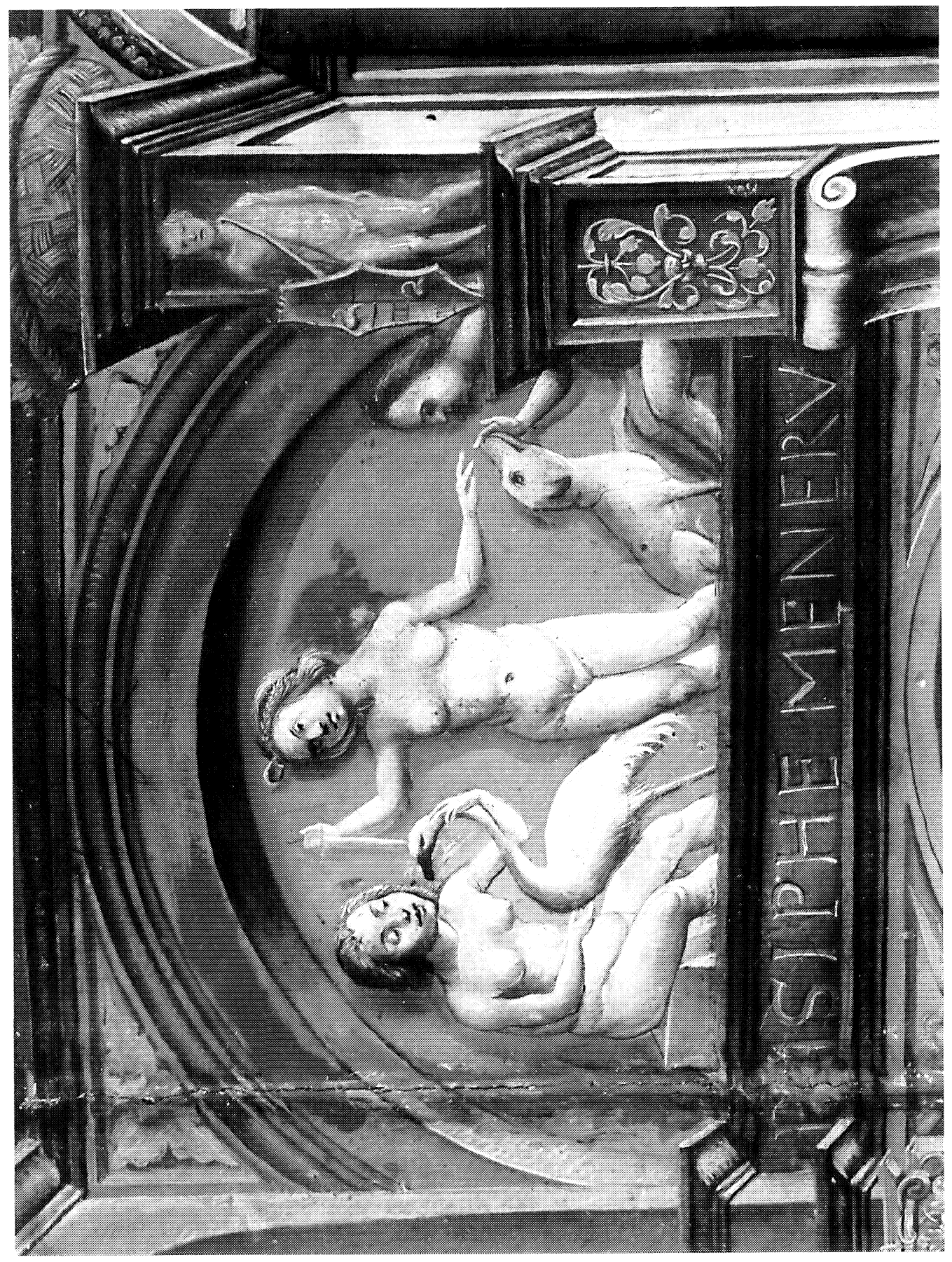

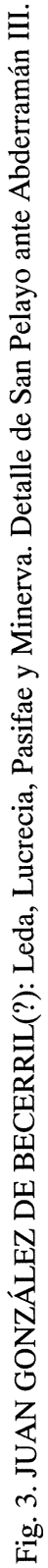




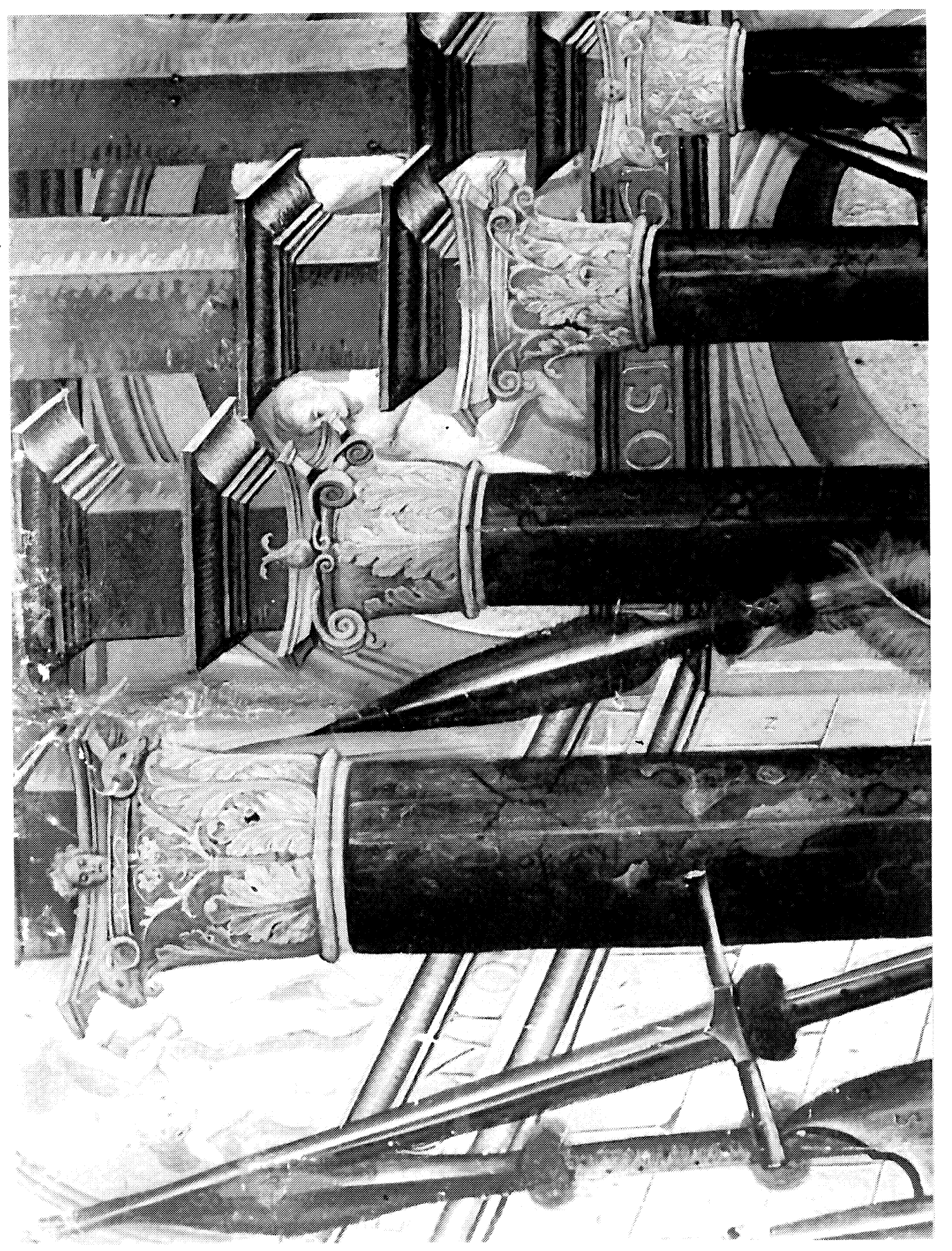

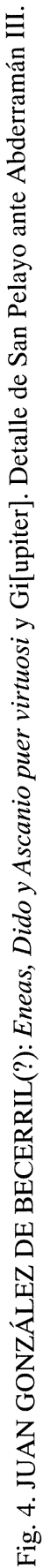




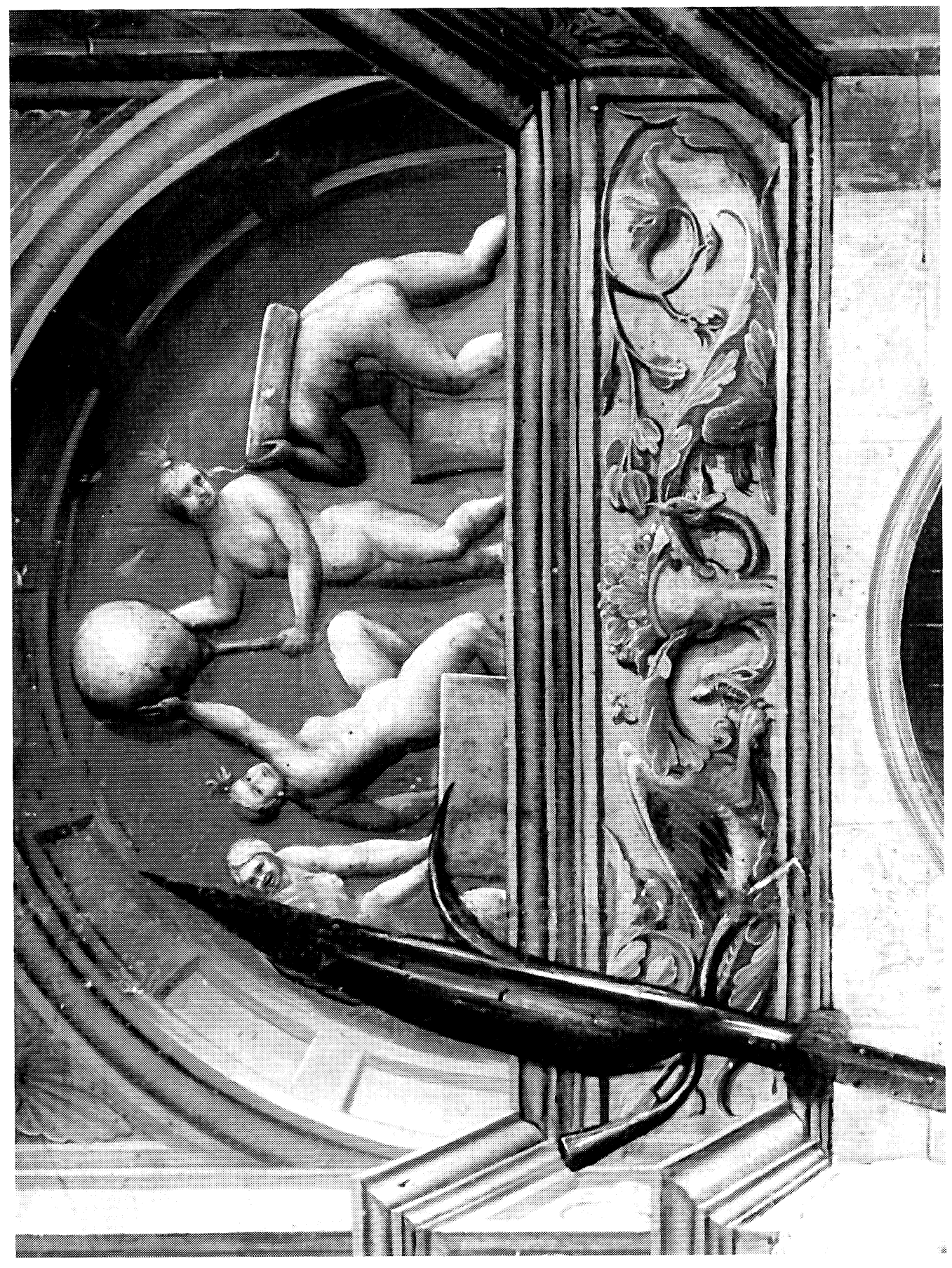

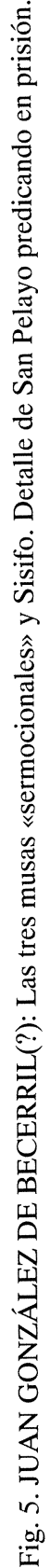

